\title{
Minimizing the environmental disasters through sustainable development strategies: an African sample
}

\section{Valentine James}

Valentine James, "Minimizing the environmental disasters through sustainable development strategies: an African sample," Proc. SPIE 9664, Ninth International Topical Meeting on Education and Training in Optics and Photonics, 966424 (24 October 2005); doi: 10.1117/12.2207790

SPIE Event: Ninth International Topical Meeting on Education and Training in Optics and Photonics, 2005, Marseille, France 


\title{
Ref ETOP105
}

\section{Minimizing the environmental disasters through sustainable development strategies: an African sample}

\author{
Dr. Valentine James
}

\begin{abstract}
s
International Conference on Energy, Environment and Disasters - INCEED2005, Charlotte, NC, USA - July 24-30, 2005 MINIMIZING THE ENVIRONMENTAL DISASTERS THROUGH SUSTAINABLE DEVELOPMENT STRATEGIES: AN AFRICAN SAMPLE Valentine James, Ph.D., CES Professor and Dean, College of Humanities and Social Sciences, Fayetteville State University, 1200 Murchison Road, Fayetteville, NC 28301-4298 The ecological systems of Africa are facing tremendous pressure due to development.

Planned and deliberate development efforts usually pay great dividends because the environment is usually taken into consideration during the planning, construction, and implementation phases of such development.

The operationalization of sustainable development concepts provide a mechanism for safeguarding against the negative ramification of extraction of natural resources and the placement of structures (urbanization) in the natural environment. In this paper, the author discusses the theoretical and practical aspects of sustainable development in Africa. The author uses a case study in Kakum, Ghana to illustrate how the theory of sustainable development is operationalized in order sustain communities, protect the natural environment from the disasters of development and to sustain the economy and culture of a society.
\end{abstract}

\section{Summary :}

Hello all. How much we have learned from one another! Our thanks again for your close attention to this weekl's concluding topic and for your wide-ranging responses.

Throughout this conference, respondents have pointed out that development and disasters are deeply intertwined and both cross-cut by gender concerns-as we know empirically, from specific disasters in particular places, if not yet in our theory and analysis.

This week, our focus was directly on recognizing links and addressing gaps, offering strategic recommendations for change.

Postings from development workers, government officials, researchers and others very clearly demonstrated how vital a gender perspective is in developing an integrated approach to disasters and development. It was very clear to respondents, first, that the root causes of disasters cannot be divorced from development processes; secondly, that planning and action in both sectors cannot be divorced; and third, that gender differences and inequalities are a significant part of the social context in which development and disasters alike unfold.

On the first point, the ।"base life issuesl" or daily living conditions of disaster-vulnerable people were clearly traced to underlying social processes resulting in poverty, marginalization, and disempowerment. Hence, as Francoise Coupal (Canada) wrote, I"Natural disasters need to be seen in a much wider socio-economic context as [they] simply make more visible underlying and already existent vulnerabilities and inequities.।"

This link was articulated in general terms and specific accounts: 
The same things that make Nicaragua vulnerable to the effects of natural hazards (poor health care, poorly constructed infrastructure, government committees/ministries that do not have the capacity, both in terms of resources and experience, to respond, etc.) are all part of structural poverty. [Sarah Henshaw, World Food Program, Nicaragua]

[T] he poverty of the poor living in a country like Bangladesh or Somalia would be difficult to break-down into those who are poor as a result of the socio-economic conditions in their countries (most of which are also linked to the international economy, thus making a compartmentalized analysis difficult), and those who are poor because of chronic drought/flooding, slow-onset disasters or rapid-onset disasters. . . Minor shocks/stresses are chronic in many places, and greatly diminish the capacity of people to deal with life routine challenges, let alone extraordinary events. [Fainula Rodriguez, International Institute for Disaster Risk Management, Philippines]

Indeed, fundamental conditions of inequality and unsustainable development constitute a daily disaster for millions around the globe. It was suggested by Brian Moore (South Africa), for example, that apartheid was in effect an extended ।"disasterl" for the vast majority of this nationl's people. As is so often the case after disasters, it too leaves its survivors at increased risk of subsequent disasters. Lack of attention to sustainable development in planning decisions was also reported from Egypt, where development pressures also put new urban migrants at increased risk of disasters.

Women and men who leave their traditional ways of life (often considered poor or marginal) for many reasons (e.g. politics, environmental degradation, diminishing feasibility, raised expectations of what they should be getting from life) often leave behind them their access to and control of natural resources. When they move to urban places they become more dependent on a salaried or entrepreneurial lifestyle, potentially poorer and more vulnerable without a back-up agrarian way of life. The demand for non-municipal environmental resources such as fuel wood and water certainly increases proportionally. . . resulting in over-harvesting and contamination in the immediate environments. . . [and] potential effects on ground water and waste disposal. . . Very often, the result is that families are fractured as the need for migrant work to some other place increases. [Angus Graham, Independent Consultant, South Africa]

As a result, lots of their urban and rural planning for development is creating a real threat which can lead to a natural disasters. Supplying water with no wastewater management can create a natural disaster, especially in hilly calcareous areas as. . . acids from organic matter in the wastewater can create [over] time serious fractures, leading to land sliding-which happened in one of the suburbs of Cairo. . . Adopting the concept of sustainable development is a must if we are really serious about reducing natural disasters and minimizing their horrible economic and socio-economic implications on both men and women. [Samia Galal Saad, Advisor to the Minister of State for Environmental Affairs, Egypt]

On the second point, while development work and disaster management work are generally distinct at the organizational level, the effects of their initiatives in hazardous environments are highly intertwined. Indeed, the same errors are made by both. Whether delivered by development or relief agencies, short-term emergency relief fails to address either the root causes of poverty and inequality or the root causes of vulnerability to disasters-and must therefore fail to address interlocking vulnerabilities and capacities.

In many situations, there is a need to implement quick relief projects, focusing on the delivery of goods for I'basic needl' (i.e. food, water, shelter, health, etc.). But, in the same situations 
the effects of the natural hazard on the communities is a factor of chronic poverty. Therefore, short-term food aid or house building does little to address the root causes of such massive destruction. [Sarah Henshaw, World Food Program, Nicaragua]

Short-sighted relief or recovery programs, whether delivered through development projects, relief agencies or government offices, easily increase dependency and undermine local peoplel's personal, organizational, and cultural capacities. As aid agencies often turn to women to distribute food aid, for instance, working the aid system becomes I"part of womenl's survival strategies.I" In Nicaragua following hurricane Mitch, it was reported that this created new divisions among women forced into competition over outside relief.

On the third point, it was observed that gender fundamentally shapes the conditions of daily life in which national development and particular environmental events unfold. In households and families, for example, gender hierarchy and the gendered division of labor profoundly influence how people interact with their immediate environment, as was discussed earlier in this conference. There can be no arbitrary division of gender, economics, and the environment:

According to the Western Ukrainian experience, where floods were the results of human activity [forest cuttings], I am sure that poverty is one of the main reasons of unsustainable environmental management. Women constitute the most part of the poor in the world. Being more responsible for familiesl' well-being, they very often use environmental resources to provide pure survival, without thinking about far future. So, the most urgent action should be taken to decrease womenl's poverty. [Oksana Kisselyova, Liberal Society Institute, Ukraine]

Haddas Wolde Giorgis (Ethiopia) noted how critical it is to understand gender equality not as a ।"womenl's affairl" but as a positive ।"development gainl" in a more equitable, sustainable and safer world. From this perspective, promoting gender equality is an integral part of promoting vulnerability reduction and more sustainable and equitable ways of living within and between the nations of the world.

We often tend to discuss sustainable development and disaster prevention as two separate l'componentsl'. However, fundamentally in both aims are similar. Sustainable development is not reachable and incomplete unless disaster prevention is an essential element in it, and disaster prevention is not something which can be discussed removed from development. Gender as an issue is in-built, and cuts across, therefore. . . in reaching gender equality the methods of analysis and tools of application can be the same. [ Madhavi Ariyabandu, Programme Manager- Disaster Mitigation, ITDG South Asia]

This weekl's discussants clearly supported the need for a gendered approach to sustainable development and disaster prevention. They called further for approaches supporting womenl's empowerment. The strategic recommendations made addressed the need for change in three, interconnected sectors: governments (at all levels); organizational practices (in disaster and/or development agencies or groups); and broader social changes. The need for education was unifying theme to which respondents most often returned.

Regarding governments, respondents called for increased representation of women in government ministries dealing with environmental issues; advocated forms of local and national governance which accord representation and active roles to all stakeholders; identified the great need for policy-making more informed by knowledge of links between gender, development and disasters. In this account from Gujarat after the 2001 earthquake, more innovated government/corporate partnerships were urged: 
A recent good practice seen towards developing innovative avenues for earthquake affected artisans in Gujarat was one where the National Institute of Fashion Technology of India worked with the artisans to create new, market-friendly products using existing skills. Rustic ironsmiths are now producing fancy designer knives instead of only spades that they used to make earlier. Rehab is not the work of NGOs and social workers alone, but entities from other sectors need to do their bit. [Anshu Sharma, SEEDS, India]

Regarding development and disaster agencies, the views of commentators echoed the slogan I"Development that is not engendered is endangered.।" Taken as a whole, this weekl's discussion suggests a wide range of strategies toward this end. First, as they have throughout this conference, contributors strong urged more community-based and participatory approaches.

Back to the future? To the degree that local initiatives are likely to be sensitive to cultural contexts and to indigenous skills and abilities, womenl's expertise and knowledge are more likely to be visible and valued. Non-bureaucratic programming grounded in local communities seems to engage women and men more equitably, whether the issues are environmental management, sustainable development, or disasters.

Disaster risk reduction has a direct link with environmental resource management at the community level. Can we not take lessons from the l'earlier modell' where women had more control over resource management and try to recreate the same in todayl's context? This will include shifting the management role back to communities, particularly to women [where] they were playing a central role in the earlier model. . . and bringing back the community concepts into life in ways suitable to todayl's context. [ Madhavi Ariyabandu, Programme Manager- Disaster Mitigation, ITDG South Asia]

An old but still relevant issue in development work in general is the participatory approach could this not be a policy goal also when it comes to catastrophe issues? The grassroots perspective and including these issues at local levels of development planning would necessarily have to consider the cultural, economic and political divisions of gender categories. [Susann Ullberg, CRISMART Crisis Management Research and Training. Stockholm, Sweden / Merlo, Argentina]

Lessons learned about gender in armed conflict may be applicable in many, though not all, respects. Certainly, participatory approaches are more gender equitable ways to reconstruct social life in the aftermath of natural disasters and after war, and can help articulate new visions of the future:

This bottom-up approach has the added advantage of being close to vulnerable populations which most top-heavy. . . efforts never even come close to. In addition, it increases the likelihood to involve women. . . A gender-sensitive focus can change this ।"invisibilityl" of women and allow a utilization of previously un- (or under-) tapped potential of womenl's resources in preventive efforts. This should also increase the likelihood of obtaining gendersensitive information that can make responses more appropriate to groups at risk. . . It also opens up the opportunity for inviting a different set of views when deciding upon what response options might be most adequate. [Susanne Schmeidl, Swiss Peace Foundation]

Secondly, mainstreaming gender analysis was urged as a way to avoid reinforcing inequalities and stereotypes. If only I"seen as a matter of l'compliancel' to ensure eligibility for funding, $\mid "$ implementing gender perspectives systematically is nonetheless an educational 
strategy potentially fostering a more holistic approach to development and disasters. Gender analysis tools can be used to promote gender-fair design, implementation, and evaluation of projects, to the benefit of men and women alike:

Men may demonstrate heroic and stoic behaviour, but they are also extremely vulnerable following a disaster when their loss of livelihood becomes a reality. Women often need psycho-social support later on. This was seen with Hurricane Mitch, the internal war in Colombia and the earthquake in El Salvador. Development organizations can take practical steps by ensuring that their policies and practices do not perpetuate these stereotypes, by involving both women and men in disaster relief work and ensuring that disaster response are sensitive to gender, age and ethnicity (such a disaggregated analysis is still not commonplace among aid and relief organizations). There is also a need for practical gender analysis tools that help demystify these stereotypes and provide practical strategies so that the potential of both women and men are realized. [Francoise Coupal, Mosaic.net International, Ottawa, Canada]

It is time for disaster prevention initiatives and programs, starting from the policy and institutionalized mechanisms to review for their gender sensitivity, if they analyze, present and have indicators considering menl's and womenl's need, interests and opportunities/challenges separately rather than talking about the people. [Haddas Wolde Giorgis, World Bank, USA]

Third, the organized efforts of people across these sectors must not only advocate but demonstrate gender equality. Brian Moore (South Africa) offered an example of womenl's proactive involvement in community work. While I"more women are selected for development or disaster committees, l" he noted the tendency for organizations to adopt a Western I'volunteerl' mind setl' tending to exploit women, principally by failing to materially compensate their time and skills. To counteract this, he urged:

Development of participatory value structures and a constitution which insures that both genders and all members of the team are involved in the management, development and decision-making processes. . Know what is wanted in advance, be prepared to pay for it and demand the results offered by training organisations. [Develop] community and family education programmes to. . . develop value structures and respect for the opposite gender. [Brian Moore- Mthimkhulu Training, Durban, South Africa]

In thinking about how gender equality goals relate to sustainable development and disaster prevention, commentators returned again and again to education. Education and womenl's empowerment were seen as joined-not simplistically or universally, but integrally joined.

Many different educational strategies and goals were promoted. Participants urged, as they have in earlier discussions, more careful and gender-sensitive vulnerability assessments and other ways of improving the knowledge base of ।"decision-makers in developing countriesand in developed countries, for that matter, since much advice seems to come from there!।"

Gendered-targeted education geared to women was advised, whether through practical action tips or l"hybrid knowledgel" built on formal and informal expertise:

A targeted awareness raising should be promoted amongst women. There is a need to help the public help themselves. As women are generally the l'household managersl' it is important that they be given targeted information that can be useful for them. [Ana Lisa 
Vetere Arellano, European Commission DG, Joint Research Centre Institute for the Protection and Security of the Citizen, IPSC Natural Risk Sector]

I would recommend that engineering and science education, especially in geology, chemistry, and biology, be promoted for women in disaster-prone areas. In the wake of disaster, communities want to understand the science of what has happened, and it is empowering for ordinary people to have these tools at their disposal. Hybrid knowledge, combining formal science with local knowledge of plant and wildlife populations can create a broader, more effective understanding of the impacts of disasters such as hurricanes. [Ann Larabee, Michigan State University, US]

How to involve women in reducing environmental disaster? First of all, to educate them through educational programmes at all levels (beginning from kindergartens and ending the special trainings for environmental managers), to provide awareness rising campaign in communities through mass media, NGOs etc. We have very good NGO practice (Hot Line Eco-Telephone), which provides the population with environmental information. The [majority] of calls [come from] women. [Oksana Kisselyova, Liberal Society Institute, Ukraine]

Others urged more holistic, ।"humanizedl" forms of education, to nurture more equitable relations between all people and their environment:

Sensitive Education. Education, particularly higher education, be taken out of its totally career oriented mode and appropriately humanized to inculcate respect for living environment and fellow beings. . The issue here is not just integrating gender equality goals in development and disaster management, but to make the processes sensitive and humane. That would ensure integration of gender equality and much more. [Anshu Sharma, SEEDS, India]

Cultural learning from l"gender respectingl" communities can provide guideposts to more gender-equitable and disaster-resilient communities. Brian Moore made this point about South African Hindu families in which I"both women and men are highly accepted in their roles as organisers of development and large players in disaster relief [and] leaders are found amongst both genders.I" Insisting that gender equality be concretely manifest in community work rather than an abstract goal, he urged research and education about successes:

In order for holistic development to take place the facilitators of gender equality need to live gender equality, be gender equal and be able to teach the values that allow genders within extended families to be equal from the cradle to the grave. A study of the Hindu South African families and communities that succeed in gender equality could fast track the development of women in development/ disaster relief. This is linked to the roles played in households where men cook, serve food at functions and hold their partners in great esteem. This extends to children where an older child, irrespective of gender can care for a baby. . [Brian Moore- Mthimkhulu Training, Durban, South Africa]

Still others focused primarily on education as a means to increase self-esteem and promote critique and social change of the status quo. Socialization to prevailing inequalities disempowers new generations from charting new ways forward. Conversely, simple literacy and |"basic usable educationl" fosters l"economic independence, gender respect, [and] ability to take control of opportunity and [manage] disaster relief," Brian Moore argued [South Africa]. Revision of schoolbooks and other materials which convey demeaning racial 
and gender images is needed, as are I"specific and intensive informationl" campaigns targeting rural and illiterate women, educating them about their human rights.

This I"disasterl" [of apartheid] will be perpetuated until programmes based in the cultures/beliefs of the people are introduced to grow group and individual self esteem. Until these base issues are resolved, the challenges to gender equality in major projects, disaster or developmental relief, will not be effectively integrated. [Brian Moore- Mthimkhulu Training, Durban, South Africa]

The first handicap for [womenl's] emancipation and full integration to the society. . . remains illiteracy, aggravated today by. . . insufficient information. . . [From] my point of view, obligatory education of the girl child should be at the base of any strategy. Governments and NGOs all talk and pretend to work for it, but here in Africa, we still find girls who canl't afford school. [Madeleine Memb, Journalist, Cameroon]

[E]ducating and informing women about social change-what? why? who gains/losses? how to bargain for success and win?-becomes very important. Addressing the social issues in natural disaster, including women as participants and decision-makers having a voice. . . is very important. [Haddas Wolde Giorgis, Centre for Human Environment, Ethiopia]

Whether addressing the need for change in government or nongovernmental sectors, program-targeted training or consciousness-raising education, respondents see enormous possibility in education about how and why gender is so central a concern in the work ahead to build safer, more equitable, and disaster-resilient communities. The possibilities are enormous:

When women acquire positions and experience in planning and decision-making the first step to reducing vulnerability has begun. With this knowledge, I believe we instill the fact that women are one of our greatest assets. Women in leadership positions need to encourage others to be an active part of what is going on in their communities. They have to instill a vision that is understood and supported by women and men alike. When we empower women, we provide an avenue to connect them with others who feel the same as they do. Working together the process can begin to facilitate positive changes. Like the ripples of a pebble in a pond, the effects can be far reaching. [Cathy Diehl, Emergency Management Coordinator, Utah, US]

I add only that your thoughtful and generous responses have made this conference quite extraordinary. These conference documents will prove extremely valuable to others-who will benefit, too, from reading your postings in their entirety!

Please take a moment over the next few days to forward along any last-minute questions, answers, or concerns. Specific recommendations for topics to be taken up by the Expert Working Group in its forthcoming Ankara meeting are especially invited.

With warm regards to each - 